\title{
E-government Readiness Assessment for Government institutions in Burundi
}

\author{
Steve Cedric Bizimana \\ Center for Interdisciplinary Research and Analysis on the Development of the Great Lakes Region (CARID-RGL), Lake Tanganyika \\ University, Bujumbura, Burundi
}

Email address:

bizimanastevecedric@gmail.com

\section{To cite this article:}

Steve Cedric Bizimana. E-government Readiness Assessment for Government institutions in Burundi. International Journal of European Studies. Vol. 4, No. 1, 2020, pp. 1-8. doi: 10.11648/j.ijes.20200401.11

Received: September 12, 2019; Accepted: September 30, 2019; Published: May 28, 2020

\begin{abstract}
Electronic government (E-government) refers to the use of Information and Communication Technology, and specifically the Internet, as a tool to achieve better government. Indeed, Information and Communication Technology have been introduced in the government sector in the past two (2) decades in an attempt to achieve greater operational efficiency and effectiveness and e-government development is one of the most important factors of public sector rationalization, as well as faster countries' development. Given the growing development of e-government strategies worldwide, the Government of Burundi has also recently taken several measures by introducing e-government services for ensuring easy access to government information and success. The paper has then assessed the e-government readiness of several Government institutions in Burundi. The paper has used a qualitative approach and a framework provided by the European Commission to assess the e-readiness of public institutions. Several interviews with key respondents and an extensive desk review were conducted to ensure an effective data collection process. Hence, the paper revealed that Burundi has one of the lowest e-readiness rate worldwide and comes in at the low end of most of the rankings. The major causes being the lack of political will and the development level of the country. Egovernment being a good governance reform, the Government of Burundi must ensure a proper political will and sound administrative activities to make the journey to an implementation of e-government more effective.
\end{abstract}

Keywords: E-government, Readiness Assessment, Government Institutions, Burundi

\section{Background}

Electronic government (E-government) refers to the use of Information and Communication Technology (ICT), and specifically the Internet, as a tool to achieve better government [1]. It is the use of ICT in government to deliver services to citizens, businesses and across government. Egovernment enables government to deliver services to citizens conveniently (G2C system); businesses cost effectively accesses government services (G2B system) and inter-government agency interaction (G2G system) [2]. Indeed, ICT's have been introduced in the government sector in the past two (2) decades in an attempt to achieve greater operational efficiency and effectiveness [1] and egovernment development is one of the most important factors of public sector rationalization, as well as faster countries' development [3, 4].

According to Chipeta, e-government can be traced way back in the late 1970s in the United States of America during New Public Management (NPM) reforms. The aim of these reforms was to transform government to be result oriented, efficient and customer centered [2]. E-government promotes then an open government system which is very critical to the modern government. It is a major criterion for development and today's drive towards e-governance in many parts of the world can be considered part of this wider developmental goal [2, 5]. Furthermore, the so-called ICT revolution, initially centered on deploying communication and connectivity infrastructure, has radically evolved since the end of the 1990s. Currently, governments use ICT for intragovernmental communication and for implementing services to inform and communicate with citizens, and also for promoting citizen participation in democratic processes and governance [6, 7] which leads to (i) improved efficiency, convenient and faster access to government services; (ii) increased transparency, accountability of government 
functionaries; (iii) reduced costs of administrative services; (iv) and improved democracy, among other things [8].

In the light of the above-mentioned facts, ICT's are then critical tools in fighting poverty and uplifting socio-economic and living standards of the people. They have the potential to empower people to overcome development obstacles, address social problems and strengthen democratic institutions. The use of ICT's in the public sector is an alternative way of implementing the six (6) functions of Public Administration, namely (i) policy, (ii) finance, (iii) organizing, (iv) staffing, (v) determining work procedures and (vi) controlling [9].

Moreover, although the term e-governance is primarily used to refer to the usage of ICT's to improve administrative efficiency and the general approach to e-government is through the Internet, e-government can also be delivered using non-Internet Protocol (IP) devices such as telephone, fax, PDA, SMS, MMS, GPRS, Wi-Fi, RFID, biometric identification and smart identity cards as well as community radio [10, 11]. For instance, the contribution of mobile phones and technologies is highly acknowledged in the advancement of developing countries in e-government implementation, particularly in the provision and adoption of online public services by governments and citizens [12].

Given the growing development of e-government strategies worldwide, the Government of Burundi (GoB) has also recently taken several measures by introducing egovernment services for ensuring easy access to government information and success. However, despite efforts from the government in implementing e-government, it is still at the initial state due to the lack of telecommunication infrastructure, only $5 \%$ of population use internet and Burundi has one of the lowest score in e-government $(6 \%)$ [10]. Generally, the use of tools such as ICT in service provisioning allows people to immediately access services in real time and within a few clicks on the internet. In a typical government set up, most transactions between citizens usually happen right in government offices [2]. Currently, a good number of public services are manual based in Burundi. Additionally, before submitting their application forms, citizens have to go through different cumbersome procedures and processes filling different forms from one office to another spending many hours. This is usually because the process is equally manual and slow.

In general, e-government has several dimensions. Every dimension requires leadership, cross-coordination and knowledge, all integrated with an ICT strategy to achieve the vision. The availability of an e-government framework for assessing the ICT readiness in public sectors is critical in developing effective e-government policies and strategies. The design of e-government readiness assessment frameworks requires comprehensible measurement of the assessment design that determines factors clearly derived from information needs, which influences the other factors. E-readiness is then the aptitude of an economy to be a participant in the digital world [1].

It is against this background that the study intends to investigate the e-readiness of GoB institutions. Indeed, little research has been endeavored on e-government in Burundi while no research has been undertaken to investigate the readiness of e-government at all. This is what makes this study very unique and significant. Its intent is to serve as an eye-opener for policy makers in planning and designing sound and effective e-government policies and strategies.

\section{Methodology}

The research study used a qualitative study design to gather the relevant data because the researcher wanted to provide a detailed picture of the subject study and thus relied on qualitative tools [13]. A qualitative approach can also be selected because of its relatively smaller sample in which the researcher acquires a comprehensive overview of different contexts to draw conclusions rather than statistical measures of results [12]. Hence, interviews, a desk research and a content analysis of several official websites were selected as data collection tools. The design of interview guides and the systematic analysis of literature through desk research were guided by the comprehensive framework for e-readiness assessment suggested by the European Commission (EC) [14]. This framework helped identifying areas of investigation deemed important to e-government readiness (e-readiness) at national level.

Moreover, the framework has divided key elements of egovernance into two (2) sections. One section is "digital elements" and is directly connected to technology. The other section is "analogue elements" and supports the technology with regulations, organization, financing, change management, raising awareness and political will. According to EC experts, these sections are not opposed to, but rather complement, each other. A selection of key digital elements included (i) Government portal; (ii) Digital databases and digitization of records; (iii) Secure exchange of data; (iv) Secure digital identity and digital signature; and (v) Infrastructure issues while key analogue elements included (i) International frameworks; (ii) Legal framework (legislation and regulations enabling digital transactions and protecting privacy); (iii) Coordinating institutions; (iv) Political will and change management; (v) Access to services; and (vi) Awareness raising [14].

Several individual interviews were then made with purposively selected key respondents from several governments' institutions. The transcribed interviews were sent to the interviewees for accuracy and additional comments. The researcher ensured that the responses were recorded and verified to ensure accuracy and reliability of the findings as is suggested by Bogere and Gesa [13]. Data obtained from the interviews was analyzed qualitatively to search for patterns, similarities and differences in the approaches.

A desk research and a content analysis of official websites were conducted in parallel to the interviews to triangulate and validate data collected from the interviews. The researcher sought official documentations such as egovernment strategies, interoperability frameworks and 
architectures and evaluation frameworks, and evaluated the suitability of documents with the interviewees so to address drawbacks of desk research such as access restrictions or lack of control over data quality. Due to the nature of the research study, the inquiry also included the sources that are freely available online. Official websites constituted for instance the Government portal, several ministries', among others.

However, the researcher must acknowledge several aspects constituting the limitations of this study to a certain extent. (1) For a number of key elements, there are no indexes or other quantitative indicators, as the issues (earlier mentioned in this section) do not permit quantification but require an analytical and qualitative approach. This means that the analysis of data gathered relied on the expertise of the researcher and/or other experts' comments requested. (2) One other aspect was that the recognition of what e-governance means is, in many ways, still in its infancy in general and in Burundi in particular. Clarity of concepts is not helped by the fact that there is no coherent terminology, although with the spread of certain technical and legal solutions, such terminology is gradually being created. According to the EC, even the term "e-governance" itself is not universally used in the same way. The latter can explain the lack of clear responses of interviewees [14]. However, the researcher tried to follow the inquiry framework to insure academic consistency.

\section{Findings and Discussion}

According to Heeks, e-readiness has become sufficiently widespread as a concept to spawn a number of variants. These can be posed as an inventory of the following "ereadiness for e-government" questions. (1) Is the data systems infrastructure ready? (2) Is the legal infrastructure ready? (3) Is the institutional infrastructure ready? (4) Is the human infrastructure ready? (4) Is the technological infrastructure ready? [15] Is the technological infrastructure ready? (6) Is the leadership and strategic thinking ready? [15]. This section is structured around several points trying to respond to these particular questions regarding the GoB organizations and are presented into two (2) sub-sections, namely (i) Digital and (ii) Analogue elements.

\subsection{Digital Elements}

\subsubsection{Government Portal, Digital Databases and Secure Exchange of Data}

The central point of access to governmental online services are government service portals. Service portals play a crucial role when efficiency of public administration, public services and user centric benefits are analyzed. Such portals are the central information gateways to all government services, both offline and online [14].

Findings show that Burundi has a governmental portal (http://www.burundi.gov.bi/). The website is daily updated with information about the ongoing activities of the President in particular and the GoB in general. It also provides general information such as the weather and several links of all other important institutions, among other things.

According to the EC, the extent of digital databases and digital exchange of data is to a large extent difficult to identify. Most countries are in the process of digitizing records but in almost all cases, this process is ongoing with a lot of data still only in analogue form. This is the case of Burundi which holds more than $90 \%$ of its record in paper format [14].

In the creation of e-governance, databases provide a backbone. During the last decades, most governments have turned their data from paper to digital format or are in the process of doing so. Electronic databases are a prerequisite for many e-governance services. Key databases (often referred to as registries) normally include the civil registry (population register), the real estate registry (buildings, land cadaster and property ownership) as well as the business registry. These are main databases, as many others use data from them, while other registries tend to be more specific and in many instances link data with the main ones. Many eservices will use data from different databases, so interoperability of databases can provide important efficiency gains [14].

Modern data handling provides opportunities to use a "once only" principle, meaning that governments can only ask for information once, following which the government agencies must share the data if needed. What this means in practice is e.g. that the government cannot record the same data (like an address) in several databases, but only in e.g. the civil registry. To provide services, other government units will get the address from this registry and not ask it from the individual. This reduces the administrative burden for individuals and companies, as well as avoiding risks related to data duplication and quality. In order, not to add new risks when old ones are eliminated, there is a need to exchange digital data securely. There should not be any centralized databases, as this would provide risky single points of failure [14].

According to the EC, Secure Data Exchange Solution should meet the following criteria [14]:

1. Both sender and receiver of the data should be registered and verified, meaning identified through agreed procedures and mechanisms;

2. The confidentiality of the exchanged data should be ensured with encryption;

3. The data transactions should be timestamped, so that it is possible later to verify that at a certain moment the data in the database was as presented;

4. Electronic records should be logged and archived to ensure a legal audit trail;

5. There should be a proper legal status of data requests and answers.

Together with secure data exchange, digital information assets management should be organized, including proper information about the databases (registries), services and user rights. Digitization should not be introduced in a vacuum, but as part of a set of structural measures to support improvement 
of key databases like civil registers - improving the integrity, effectiveness, and completeness of such registries, which is not just a technology issue. The reasons for incomplete or faulty registers are manifold with cultural issues, lack of accessible contact points with authorities and fear of insufficient data protection as some factors [14].

\subsubsection{Secure Digital Identity and Digital Signature}

In general, governments are increasingly using egovernance solutions. Starting with simple governmental information websites, the trend is towards integrated services that allow interaction with citizens, like filing documents online or paying taxes. As soon as e-government services begin to include interaction, the importance of a secure identification system comes into play [14].

For use of digital services, it is essential to have a digital identity and a digital signature that are secure enough to allow transactions to have legal value. Such identities must be securely connected to the physical identity and trusted by the government. The identities may be developed for specific services (like taxation or social security) but having too many different identities risks making these less attractive to use, as people do not easily remember the various codes and log-in details [14].

In this paper, the indicator used to assess secure digital identity and digital signature is the existence of national ID's with some electronic component that can be used for digital authentication purposes. In 2013, Burundi launched a pilot program to issue machine-readable national identity cards to individuals who are 16 and older. Findings could not clear the current status of this initiative. However, in 2014, the Independent National Electoral Commission (CENI) of Burundi announced that Burundians would no longer need the National biometric ID card to register for general elections in 2015. Thus, in 2014, Burundi started a pilot for machine readable IDs, but people were reluctant to provide all information asked, such as bank accounts and properties, resulting in low turnout. It has not been possible to find data on the current status of the project.

According to the EC, interoperability frameworks are an essential part of the Whole-of-Government Approach and enable the integration of different technological platforms and solutions into common solutions and services. From an e-governance perspective, interoperability refers to the collaboration ability of cross-ministerial and cross-border services for citizens, businesses and public administrations. Exchanging data can be a challenge due to language barriers, different specifications of formats and varieties of standards and categorizations. If data is interpreted differently, collaboration is limited, takes longer and is not efficient. Hence, e-government applications need to exchange data in a semantically interoperable manner. This saves time and money and reduces sources of errors. Fields of practical use are found in every policy area, be it justice, trade or participation etc. Good examples of the benefits of interoperability frameworks in practice can be found at the European Interoperability Framework process [14].

\subsubsection{Infrastructure Issues}

Providing access to the internet is a key factor for developing an information society, because it serves as the foundation for delivering and using e-government services. Access to the internet is usually provided by private telecommunication companies, who also run telecommunication networks. Access can be by wired or mobile networks, with mobile becoming increasingly common. For wired networks, the last meters at home or in the office can be either by cable or wireless access point connection (Wi-Fi) [14].

According to the EC, indicators to assess the state of infrastructures are (i) fixed broadband subscriptions; (ii) fixed telephone subscriptions; (iii) mobile cellular subscriptions; (iv) investments in telecom with private participation; and (v) secure internet servers. These indicators are important, in particular to assess the current state of the digital transformation process in specific countries as the access provides a core fundament for successful egovernance [14]. Tables 1 shows the status of infrastructures in Burundi from 2014 to 2016.

Table 1. E-government Infrastructures in Burundi (2014 - 2016).

\begin{tabular}{llll}
\hline $\begin{array}{l}\text { Fixed Broadband (/100 } \\
\text { people) }\end{array}$ & $\begin{array}{l}\text { Fixed Telephone (/100 } \\
\text { people) }\end{array}$ & $\begin{array}{l}\text { Mobile Cellular (/100 } \\
\text { people) }\end{array}$ & $\begin{array}{l}\text { Investment in Telecoms with } \\
\text { Private Participation (US \$) }\end{array}$ \\
\hline 0.03 & 0 & 26 & 0 \\
\hline
\end{tabular}

Source: Collected data.

In statistical terms, during the period of time from 20154 to 2016, Burundi has (i) 0.03 connections per 100 inhabitants, (ii) 0 fixed telephone (/100 people) and (ii) 26 owners of mobile cellular per 100 people. Investments in telecoms with private participation were very low and represented US \$ 0 while only 1 secure internet server could be found over 1000 inhabitants. This represents a very low development of E-government infrastructures.

Notwithstanding, the EC noted that the access to broadband internet is generally not very well developed in
Africa. Government offices and public authorities tend to have access to internet, although speeds may not be very high, but among the population the access - albeit with important variations between countries as well as between regions in countries - is generally not good. This is especially true for fixed broadband, where several countries have below 0.1 connections per 100 people. However, the penetration of mobile telephony and to some extent of mobile internet is high in almost all parts of Africa [14]. 


\subsection{Analogue Elements}

\subsubsection{International Frameworks}

A number of international initiatives exist to benefit from the absence of physical borders in cyberspace and promote international cooperation. The 2030 Agenda for Sustainable Development adopted by the UN General Assembly in 2015 highlighted the importance of ICT. Thus, the UN promotes initiatives linked to connectivity and infrastructure such as the United Nations Broadband Commission for Sustainable Development. These activities provide support to countries to make it possible for them to enjoy the benefits of the technologies, but there are also a number of international initiatives that benefit from what the technologies permit. In Europe, the EU Digital Single Market is a very important such idea. In Africa, there is no well-developed single market analogue to the European one, but regional organizations provide fora for cooperation on different issues, often modelled on, or inspired by, the EU [14].

As the EC stresses it, the efficiency of supporting international frameworks for digital technologies cannot be measured with quantitative indicators but is based on experts' analysis [14]. Except the EAC International frameworks more explained below, the researcher could not assess the involvement of Burundi in international frameworks.

\subsubsection{Legal Framework}

According to principles of the rule of law, the governance of a country is conducted through legislation, and all activities, including those of government institutions, should be carried out in accordance with the law. Therefore, it is vital to have appropriate regulation in place for e-governance [14].

For assessing the performance of the e-government regulatory framework, the EC proposes two (2) main indicators, such as (i) the existence of data protection legislation; and (ii) laws relating to ICTs [14]. For the Burundian case, no data protection legislation has been yet enacted even if a National ICT Policy Plan (2010 - 2025) has been adopted.

In 2010, the East African Community (EAC) has developed and adopted the EAC Framework for Cyber-laws which recommended each member state to develop a regulatory regime for data protection. However, it didn't make no specific recommendations as to the content of legislation. The EAC is currently working on establishing a legal framework regarding cyber laws-that provides guidelines on the enactment and enforcement of laws that promote the deployment of egovernment and e-commerce services.

Burundi ranks at 2.4 at the Laws relating to ICT's index (2016). This index is measuring (i) the quality of regulations pertaining to ICTs, (ii) the capacity and the role of ICTs in driving innovation as well as represents (ii) the level of sophistication for ICT related laws in a country. ICT consists of for example, (i) e-commerce, (ii) digital signatures and (iii) consumer protection areas. The higher the index is, the more developed and sophisticated laws are enforced in a country. The scale moving from 1 (highly undeveloped) to 7 (well-developed).

The EC stresses that it is a common misconception that egovernance demands a lot of designated legislation. This is not the case and such legislation may even be harmful, as it risks creating a parallel system of governance rather than improving governance. Only a few areas necessitate special legislation. This includes recognition of electronic identities and signatures as well as electronic documents. This can be done through special laws or amendments to existing laws, such as administrative and criminal procedure legislation and contract law. In addition, protection of privacy is essential, including specifically data protection. Such protection is a constitutional right in most countries in the world as well as being protected by international human rights instruments. The multitude of laws implicated in a transition to egovernance means that there is no single type of law to search for or any existing comprehensive international listings of the legal situation in different countries [14].

\subsubsection{Institutions Coordination}

There is a need for high level coordination of egovernment activities between various units of the government as well as other agencies, to identify the capacity to introduce e-government elements into the functioning mechanisms of government institutions. The idea of coordination is not to centralize decision making and technical capacities, but to support the innovation and service delivery modernization in every government institution in a harmonized manner, avoiding duplication and overinvestment [14].

Furthermore, it is appropriate to separate the levels of decision making: strategic decisions, supervision, coordination and implementation are better kept in separate institutions. There should be clear roles, mandates and responsibilities between the institutions. In addition to existing organizations, it may be necessary to create a new central coordination unit or otherwise to explicitly give this task to an existing organ [14].

A regulatory body named the Regulatory Agency for Telecommunications (Agence de Régulation et de Contrôle des Télécommunications - ARCT) is an agency responsible for regulating communications in Burundi. This body regulates by (ii) processing applications for licenses, (ii) establishing standards for equipment and operation, (iii) arbitrating disputes, (iv) ensuring fair competition and (v) managing the frequency spectrum. A Ministry of ICT has been instituted with the 2015 government which mission is, among others, to (i) develop and implement a policy to expand, modernize and rationalize national and international telecommunication networks; (ii) promote the development of electronic communications and ensure the establishment of a legal framework relating thereto; (iii) monitor reports and maintain relations between the Government and Parliament; (iv) increase the supply of electronic communication services and facilitate their universal access; (v) facilitate Burundi's cooperation with other relevant ministries, the promotion, monitoring and implementation of 
ICT and offer the relevant training programs; and (vi) design a coherent policy for the promotion and development of modern telecommunications technologies. The two (2) bodies are responsible for the regulation, interoperability and coordination of other GoB institutions.

The mandate of the ARCT goes in line with what the EC has urged about such regulatory body. it indicates that the central coordination unit must have clear mandate either from the Parliament, President or Cabinet of Ministers. It is important that the central coordination unit reports directly to the Prime Minister (or possibly President or Vice-President (s) in Burundi's case), to make sure that decisions and progress will have high level political support and appropriate resources. Nonetheless, the central role given to the ministry in charge of ICT related matters can hamper the effective implementation of e-government. It further stresses that if a ministry is in charge of e-governance development, there is a danger that other ministries - normally horizontally placed hierarchically - may question the basis for this one ministry to determine issues for all ministries. It is recommended to centralize development of the policies and standards and decentralize the implementation [14].

\subsubsection{Political Will and Change Management}

To secure long-term changes, political will and leadership is required. At least a critical mass of Members of the Parliament must be aware of the benefits of e-governance, trends and progress in the country. With this knowledge, they can support the important legislative process. Personal leadership matters, both at the political and administrative level [14].

While there is no perfect measure of political will towards e-governance of a country or change management, the EC proposes the following as an assessment of the level of commitment from the political leadership: (i) Publication of a government-wide e-governance strategy; institutionalization of a coordination mechanism for egovernance; (iii) existence of a Government Chief Information Officer or a similar position; (iv) public statements from the head of government in support of egovernance; and (v) Index of Importance of Government Vision of the Future [14].

Burundi adopted a national ICT development policy late in February 2007 as an update to the national ICT strategy adopted in 2004, but it has not been implemented due to the government's focus on the post-war cease-fire issues and lack of funding. The national ICT development policy had six (6) strategic objectives such as (i) Capacity-building; (ii) Enhancement of a legal and regulatory environment; (iii) Promotion of a base infrastructure; (iv) Promotion of good governance; (v) Promotion and encouragement of private investment; and (vi) Promotion of the development of content and applications. In 2010, Burundi adopted a National ICT Policy Plan $(2010$ - 2025) in 2010. This showed the commitment for a long term e-governance framework. However, findings show that the implementation of this framework is challenging. The "Index of Importance of Government Vision of the Future" assesses to what extent the government has a clear implementation plan for utilizing ICTs to improve a country's overall competitiveness. This indicator shows indeed the government effort to improve the regulatory environment. The higher the index - the clearer the vision a government has. Coupled with the Laws relating to ICT's Index (also earlier mentioned), these two (2) indexes clearly assess the level of commitment. The Importance of Burundi's government vision index (2014 - 15) was 3.0 while the Laws relating to ICT's index (2016) was 2.4.

According to the EC, the whole e-governance implementation process is not only about technology. It is also not about transferring the services from paper to computer: it is re-inventing public services. Or even broader, it is re-inventing governance. The key question for change management is how to release energy and ideas for the reengineering of the existing public services and related business processes in the government. New skills such as computer skills, including typical office solutions as well as sophisticated software (design, planning, technical design, etc.), are needed, as well as new competences, such as analyzing big data, understanding links between public services and their impact and designing new services based on such knowledge [14].

Overcoming resistance to change is one of the greatest challenges for implementing effective e-governance. Some reforms may interfere with behaviors that are deeply ingrained in the culture of public institutions or even contradict the corporate interests of government bureaucracies. The cross-governmental nature of the changes that need to be implemented further adds complexity to this. To navigate this scenario, political leaders need to stay engaged and commit time, budget, and even political capital to the cause of e-governance [14]. Hence, an e-government strategy is essential for effective e-government implementation. A strategic plan provides a roadmap for an organization to move from its current state to its desired medium or long term future state [1].

\subsubsection{Access to Services and Awareness Raising}

A very important element of the implementation of egovernance is to increase awareness of individuals and organizations about the opportunities. Without that, there will be no usage of e-services and therefore no need to invest in them [14].

Many aspects need to be considered including [14]:

1. Cultural - individuals might be used to the existing governance culture, preferring physical visits to the offices and face-to-face contact with officials;

2. Economic - costs for access to online services may still be high for individuals;

3. Religious - in some religions, numbers instead of names (like a personal ID number) might be unacceptable;

4. Security and privacy - individuals may be concerned about how their data is collected, handled and stored.

There are no quantitative indicators for the quality of services, although it is possible to make assessments of the 
quality of a government's delivery of online services and how effectively the public sector is using digital technologies to deliver services to citizens [14]. The Government Online Service index (OSI) captures a government's performance in delivering online services to the citizens. The index computation methodology is worked out by the United Nations Department of Economic and Social Affairs and is based on expert opinion. There are four stages of service delivery: (i) Emerging, (ii) Enhanced, (iii) Transactional and (iii) Connected. Online services are assigned to each stage according to their degree of sophistication, from the more basic to the more sophisticated. In each country, the performance of the government in each of the four stages is measured as the number of services provided as a percentage of the maximum services in the corresponding stage. Examples include: (i) online presence, (ii) deployment of multimedia content, (iii) government's' solicitation of citizen input, (iv) widespread data sharing and (v) use of social networking and the scale goes from 0 to 1 . Burundi has an index of 0.0 .

The EC noted that properly introduced and applied egovernance can increase efficiency, make authorities more accessible to people and help to combat corruption. Such progress will make the country more attractive for business, including foreign investment. E-services must be part of a general overhaul of regulation, as only digitizing services that are overly complex or un-transparent will not by itself solve all problems [14].

Lastly, it is noteworthy that, in 2016, Burundi ranked on the $174^{\text {th }}$ place out 191 on the E-government Development Index (by UN); 171th/175 on the ICT Development Index (by International Telecommunication Union - ITU); and $138^{\text {th }} / 139$ on the Networked Readiness Index (by World Economic Forum - WEF). (A) The E-government Development Index (EDGI) measures e-government instructions' effectiveness in the delivery of basic economic and social services to people. It consists of three (3) most important dimensions of e-government: (i) scope and quality of online services (Online Service Index, OSI), (ii) development status of telecommunication infrastructure (Telecommunication Infrastructure Index, TII) and (iii) inherent human capital (Human Capital Index, HCI). (B) The ITU ICT Development Index (IDI) is a unique benchmark of the level of ICT development in a country. The IDI combines eleven (11) indicators on ICT access, use and skills, capturing key aspects of ICT development. The three (3) key categories of indicators are: (i) 5 infrastructure and access indicators (fixed-telephone subscriptions, mobile-cellular telephone subscriptions, international Internet bandwidth per Internet user, households with a computer, and households with Internet access); (ii) 3 intensity and usage indicators (individuals using the Internet, fixed broadband subscriptions, and mobile-broadband subscriptions). (C) Finally, The Networked Readiness Index (NRI) looks at what the different actors in society, both private and public, can do to contribute and coordinate the country's networked readiness. The four (4) key categories of indicators are: (i) the overall environment for technology use and creation (political, regulatory, business, and innovation); (ii) networked readiness in terms of ICT infrastructure, affordability, and skills; (iii) technology adoption/usage by the three (3) groups of stakeholders (government, the private sector, and private individuals).

\section{Implications and Ways Forward}

Burundi comes in at the low end of most of the rankings. It has a government portal with many services available. Even if e-governance initiatives are in their initial stages in Burundi, there could be issues with finding adequate national capacity for knowledge transfer and sustainability of reforms. The so poorly ranked position of the country may be attributed to a lack of credibly expressed political will that make serious reform work impossible or nearly impossible has been noticed. Another aspect affecting its e-readiness can be its development level explaining the very few solutions that have been adopted and the obstacles to rapid introduction of e-governance faced.

This is unfortunate because, as Alghamdi et al. stress it, egovernment services can play an important role in reforming government internal work processes to advance efficiency. In particular, improving government work processes using ICT leads to increased accuracy by providing integrated reporting systems of central and local governments. Furthermore, it also results in advanced efficiency by sharing information both within and between agencies [1].

However, on its study of e-government in Africa, the EC mitigates the current status of Burundi vis-à-vis Africa. It states that, in many African countries, data quality and data security are very poor and there are few mechanisms to address these issues. Digital signatures cannot be accepted. In most African countries, there are no institutions to coordinate and lead and drive e-governance. Key skills gaps relate to business analysis and system design, and to project management, contract management and vendor management. There are also "mindset" gaps: (i) general resistance to change; (ii) lack of customer-orientation; (ii) resistance to data-sharing; etc. Although there have been great strides forward, the fact remains that most African countries are a long way short of the computing and telecommunications infrastructure on which many Western e-government initiatives have been based. A critical pre-condition in successful e-government is an e-champion or small group of e-champions: leaders with vision who put e-government onto the agenda, who set e-government within a broader reform agenda, and who make it happen. Of all the e-readiness issues, this is probably the most critical. Hence, the limited number of senior officials who feel willing or able to champion ICTs in government in Africa acts as a most serious constraint to e-government diffusion [14].

Hafkin in turn gives a basic list of e-government prerequisites that would probably help governments to implement effective e-government and would include the following: (i) a minimum threshold level of technological infrastructure; (ii) near-universal Internet access; (iii) human 
capital (of both designers and users); (iv) legal frameworks/enabling environment; (v) political will; (vi) integration and redesign of government organization and processes; and (vii) consideration of people issues: public service culture, technophobia, reaching minorities [11].

The GoB should try to implement these strategies suggested by this scholar by: (i) achieving interoperability with mobile devices; (ii) using human intermediaries between citizens and digital infrastructure to make up for the widespread lack of ICT access and skills; (iii) building greater awareness of social and cultural issues into project design; (iv) establishing contact with local research community especially on evaluation to build a local knowledge base; (v) trying the use of Web 2.0 techniques for increased e-participation. To do this, the development of egovernment requires a holistic strategic approach that encompasses the entire public administration and is not limited to individual bodies and institutions, or individual sectors and levels of administration [11].

\section{Conclusion}

The aim of this paper was to assess e-government readiness in GoB's institutions. While many studies reviewed in this paper have emphasized that the use of ICT's can enhance a government's ability to foster development and support broad public sector reforms and good governance both within government administrations, as well as in their interaction with citizens and the private sector, the study revealed that Burundi e-readiness was one of the lowest in the worldwide. The factors underlying this current status of e-readiness may be attributed to the lack of political and development level of the country.

However, without a proper political will and sound administrative activities, the journey to an effective use of egovernment may be more hampered than it is to date. Indeed, as Hafkin has emphasized it, the keyword in e-government is government, not electronic; the emphasis needs then to be put on government and governance, not on value-free technological approaches. Moreover, e-government is not only having a government website on the internet, it is having processes that are citizens focused [11]. Government should be able to provide services using the websites and the websites should be able to efficiently provide the features that make it convenient for citizens to access services and enhance therefore accountability and transparency [2].

\section{References}

[1] Alghamdi I. A., Goodwin R. and Rampersad G. (2011). Egovernment Readiness Assessment for Government Organizations in Developing Countries. Computer and Information Science, 4 (3), 1-33 (DOI: 10.5539/cis.v4n3p3).
[2] Chipeta J. (2018). A Review of E-government Development in Africa: A case of Zambia. Journal of e-government Studies and Best Practices, 1-13 (DOI: 10.5171/2018.973845).

[3] Stanimirovic D., Jukic T., Nograsek J. and Vintar M (2012). Analysis of the Methodologies for Evaluation of Egovernment Policies. Kristiansand, Norway: 11th International Conference on Electronic Government (EGOV).

[4] Stanimirovic D. and Vintar M (2013). A Critical Insight into the Evaluation of e- Government Policies: Reflections on the Concept of Public Interest. International Journal on Advances in Life Sciences, 5 (1-2), 52-65.

[5] Madon S. (2004). Evaluating the Developmental Impact of Egovernance Initiatives: An Exploratory Framework. The Electronic Journal on Information Systems in Developing Countries, 20 (5), 1-13.

[6] UNDP - PIWA (2009). E-governance and Citizen Participation in West Africa: Challenges and Opportunities. New York, USA: United Nations Development Programme.

[7] Singh S. and Travica B. (2018). E-government systems in South Africa: An infoculture Perspective. E J Info Sys Dev Countries, 84, 1-16 (DOI: 10.1002/isd2.12030).

[8] Oni A. A., Okunoye A. and Mbarika V. W. (2016). Evaluation of E-government Implementation: The Case of State Government Websites in Nigeria. The Electronic Journal of egovernment, 14 (1), 48-59.

[9] Naidoo G. (2012). Implementation of E-government in South Africa - successes and challenges: the way forward. International Journal of Advances in Computing and Management, 1 (1), 62-66.

[10] Mugenzi T. and Priyambodo T. K. (2017). SMS and WebBased e-government Model Case Study: Citizens Complaints Management System at District of Gihosha - Burundi. IJCCS, $11(1), 67-76$

[11] Hafkin N. J. (2009). E-government in Africa: An Overview of Progress Made and Challenges Ahead. Addis Ababa, Ethiopia: UNDESA/UNPAN workshop on electronic/mobile government in Africa, United Nations Economic Commission for Africa.

[12] Mkude C. and Wimmer M. (2015). E-government Systems Design and Implementation in Developed and Developing Countries: Results from a Qualitative Analysis. Thessaloniki, Greece: 14th International Conference on Electronic Government (EGOV).

[13] Bogere M and Gesa A. (2015). Understanding research and statistical methods: A guide for East African students and researchers. Kampala, Uganda: Smart Stationers Ltd.

[14] European Commission (2019). Guidelines and Roadmap for full deployment of e-governance systems in Africa. Final Report. Brussels, Belgium: European Commission.

[15] Heeks R. (2002). eGovernment in Africa: Promise and Practice. Manchester, UK: iGovernment Working Paper Series, Institute for Development Policy and Management, University of Manchester. 